\title{
Utilization of Waste Marble Dust in Poly(Lactic Acid)-Based Biocomposites: Mechanical, Thermal and Wear Properties
}

\author{
László Lendvai $^{1}{ }^{10} \cdot$ Tej Singh $^{2} \cdot$ Gusztáv Fekete $^{2} \cdot$ Amar Patnaik $^{3} \cdot$ Gábor Dogossy $^{1}$
}

Accepted: 4 February 2021 / Published online: 20 February 2021

(c) The Author(s) 2021

\begin{abstract}
The aim of this present work was to study the applicability of waste marble dust (MD) in poly(lactic acid) (PLA)-based composites. Samples containing up to $20 \mathrm{wt} \%$ waste MD were prepared via melt blending. The attention was focused on the investigation of mechanical, morphological, thermal properties and the wear resistance of the PLA/MD composites. Regarding the mechanical properties, both the tensile and the flexural modulus improved remarkably, however, a slight loss was observed in strength and deformability. The impact toughness showed an increasing tendency up to $10 \mathrm{wt} \% \mathrm{MD}$ loading, which was followed by a marginal decrease at higher concentration. With respect to the sliding wear rate, the composite with the highest MD content showed the best wear resistance. According to the DSC measurements, the MD hampered the chain mobility of PLA, thereby reducing the crystalline ratio. Overall, composites with improved properties were developed, while the reuse of waste MD is expected to reduce the production costs as well.
\end{abstract}

Keywords Waste marble dust $\cdot$ Poly (lactic acid) (PLA) $\cdot$ Melt mixing $\cdot$ Recycling $\cdot$ Biopolymer composites

\section{Introduction}

Engineering materials play a prominent role in the modern civilization. With the increasing awareness of the society there is a constantly growing interest in using materials prepared considering environmental viewpoints as well. Therefore, in the recent years a high amount of literature has been published on the preparation of novel materials with the aim of promoting the sustainable development. Sustainability covers numerous aspects within the field of materials engineering, including the formulation of ecofriendly materials [1], the promotion of materials degradation processes (especially for polymers) [2] and the possibility to recycle waste materials [3-7].

László Lendvai

lendvai.laszlo@sze.hu

1 Department of Materials Science and Engineering, Széchenyi István University, Egyetem tér 1, 9026 Győr, Hungary

2 Savaria Institute of Technology, Eötvös Loránd University, 9700 Szombathely, Hungary

3 Department of Mechanical Engineering, Malaviya National Institute of Technology, Jaipur, India
Marble is a widely used material, especially in the area of civil engineering. With its market share of approximately $50 \%$ it is considered as the mostly used natural stone around the world [8]. According to the estimations, roughly 500 million metric tons of marble stone is mined annually [9]. About half of that comes from the quarries of four countries, namely Italy, China, India and Spain [10, 11]. India accounts for roughly $10 \%$ of the global extraction which makes it the third largest producer [11]. About $85-90 \%$ of the Indian marble is excavated in the Rajasthan region (the same marble is used in this current study). At this moment, the worldwide marble production is not expected to decrease, since the global consumption constantly grows and the estimated remaining resources-considering the current production rates-should be enough for hundreds of years. One major issue within the marble industry is the presence of marble dust (MD) waste, which is the by-product of the marble brick cutting process [12]. According to the estimations, the proportion of the MD being generated during the cutting of marble bricks is about $20-35 \%$, however, this number highly depends on the size and the shape of the cut blocks [13]. Reportedly, there is about 12 million metric tons of this MD generated in India each year, with Rajasthan state being the number one in releasing the most [14]. Stone cutting is generally performed with the help of water, which plays a triple 
role by lubricating and cooling the cutting blades, while also collecting the dust with a typical particle size below $200 \mu \mathrm{m}$ [15]. The resulting water-MD slurry is often dumped and left unattended in open areas, which causes serious environmental issues by contaminating the soil and the groundwater as well. This is considered as one of the most important environmental issues, especially in those countries, where the water resources are highly limited [16]. Lately, it is more and more common that the MD is removed from the wastewater slurry by sedimentation or coagulation in order to return the water into the consumption cycle of cutting facilities. Unfortunately, even in this case, the reuse of waste MD is not solved, so it mostly ends up being deposited at landfill sites. Unless treated properly, the MD gets dispersed by wind and rain, causing a considerable air and water pollution [13, 17]. Since proper management of MD waste would impose a heavy financial burden on extraction plants, in most cases no initiatives are carried out for further recycling. For this reason, the utilization of MD as filler or reinforcement in polymer composite fabrication could serve as a financial driver for the companies to collect and sell the dust waste instead of dumping it.

Until recently, far too little attention has been paid to the topic of utilizing MD waste in polymer composite preparation. This is especially true for polymer composites with thermoplastic matrix. Soydal et al. [18] incorporated 0-30 wt\% MD as reinforcement into epoxy resin. It was found that the presence of MD considerably increases the tensile modulus of epoxy, however, at the cost of elongation at break. In the meanwhile, it has little to no effect on the tensile strength. The authors also investigated the thermal, electrical and corrosion properties of the prepared samples and concluded that the optimum loading level of MD is $20 \mathrm{wt} \%$. Fiore et al. [19] successfully applied a plasma treatment on MD particles in order to improve their interfacial adhesion with epoxy resin. The authors reported improved tensile/flexural strength and dynamic mechanical properties when plasma treated MD was added to the epoxy matrix. In contrast, the presence of untreated particles led to a slight drop in these properties. It was also assumed that regardless the plasma treatment, the impact strength decreases with increasing MD content. Gürü et al. [20] investigated the effect of incorporating MD and fly ash into polyester resin. The authors reported an increased flexural strength and hardness with an optimal ratio of $1 / 3$ (MD/fly ash). Choudhary et al. [21, 22] studied ternary systems consisting of epoxy resin, glass fiber (10 wt $\%)$ and marble dust (0-30 wt $\%)$. It was found that both the flexural strength and the flexural modulus of the composites improved in the presence of MD, peaking at $20 \mathrm{wt} \%$ filler content. In the meanwhile, tensile strength showed a decreasing trend. The wear resistance of the composites improved in the presence of MD. The authors attributed this improvement to the enhanced hardness and thermal conductivity, as both these factors delay the exposure of glass fibers against the impinging erodent. Awad et al. [23] prepared polypropylene (PP)-based samples containing MD for civil engineering applications. In their study, the effect of MD particle size $(35-1350 \mu \mathrm{m})$ and loading level (0-70 wt $\%)$ was investigated. The results showed that the toughness of PP decreases if either the MD weight percent or its particle size increased. The authors also found that the flexural strength of PP constantly improved up until $40 \mathrm{wt} \% \mathrm{MD}$, however, above that a drop was observed. This was ascribed to the agglomeration of MD particles.

Note, that in all the aforementioned cases the researchers used synthetic plastics as matrix materials. The natural degradation process of those polymers is a very time-consuming process, which causes serious waste disposal problems. Therefore, when taking the environmental considerations and current waste management policies into account, the use of such petrol-based plastics is unfavorable [24]. As a result, the use of biodegradable materials that preferentially come from renewable resources is drawing a rapidly growing interest. Over the past two decades there has been a constantly growing research interest in the development of biopolymers in order to replace the less environmentally benign synthetic plastics. Among various commercially available bio-based polymers the most promising one is obviously the PLA. PLA is a biodegradable polyester primarily produced by chemical synthesis or through the fermentation of starch-rich agricultural products, like sugar beets, sugarcanes, corn, wheat and many others [25]. Besides, PLA is also a compostable polymer. Accordingly, under certain conditions it can be degraded into harmless compounds, like $\mathrm{CO}_{2}$ and $\mathrm{H}_{2} \mathrm{O}$. As a thermoplastic polymer, it can be processed like any other conventional synthetic plastic. It can be formed by injection molding, thermoforming, blow molding, and extrusion as well [26]. Apart from its green characteristics and excellent processability, PLA also exhibits high optical transparency and biocompatibility. Its mechanical properties are comparable to commodity plastics like PP, polyethylene (PE) and polystyrene [27]. In the meanwhile its low toughness, moderate gas barrier properties and poor thermal stability significantly limit its applications [28]. Also, its production costs are much higher than that of petrol-based plastics: while PP and PE currently sells for $0.4-0.6 € / \mathrm{kg}$, the price of PLA is roughly $6-8$ times as much $(3-4 € / \mathrm{kg})$. Hence, a large body of works has been devoted to the pairing of PLA with low-cost biopolymers, like starch $[29,30]$ and natu$\mathrm{ral} /$ mineral filler particles [31-33] in order to overcome its inherent limitations, while maintaining the biodegradability and reducing the costs.

To the best knowledge of the authors no previous studies investigated the applicability of waste MD as a filler for biodegradable polymers so far. Therefore, this present research aims at preparing composites based on PLA and 
MD (0-20 wt \%) via melt compounding. Structure-property relationships were analyzed based on mechanical, morphological, thermal and sliding wear measurements. Mechanical properties were studied based on the results of tensile, flexural and impact tests. The density of the samples and the fraction of voids were determined using standard water displacement technique. Sliding wear tests were carried out in order to determine the effect of MD on the wear resistance properties of PLA. Surface morphology of the samples was characterized by scanning electron microscopy (SEM). The crystallization kinetics of the samples were analyzed by differential scanning calorimetric (DSC) measurements.

\section{Experimental}

\section{Materials}

The extrusion grade PLA (type 2003D) of high molecular weight $\left(M_{n}=\sim 100,500 \mathrm{~g} / \mathrm{mol}, M_{w}=\sim 180,500 \mathrm{~g} / \mathrm{mol}\right.$ [34] $)$ used as polymer matrix was purchased from NatureWorks LLC (Minnetonka, MN, USA). It is a semi-crystalline polyester with $4 \% \mathrm{D}$-isomer content. It has a melting temperature of $170{ }^{\circ} \mathrm{C}$, an MFR of $6 \mathrm{~g} / 10 \mathrm{~min}$ (measured at $210^{\circ} \mathrm{C}$ with a $2.16 \mathrm{~kg}$ load) and its density is $1.24 \mathrm{~g} / \mathrm{cm}^{3}$.

The utilized waste MD with a specific weight of $2.68 \mathrm{~g} /$ $\mathrm{cm}^{3}$ was supplied by the Taj Granites Private Ltd. (Jaipur, Rajasthan, India). The SEM micrograph of marble dust is shown in Fig. 1. The detailed chemical composition of the marble powder was determined in an earlier work [21]. Its major components are $\mathrm{CaCO}_{3}, \mathrm{CaO}, \mathrm{MgCO}_{3}, \mathrm{MgO}$ and $\mathrm{SiO}_{2}$.

\section{Preparation and Processing}

The MD was washed with distilled water in order to eliminate the unwanted contaminations then dried in a drying

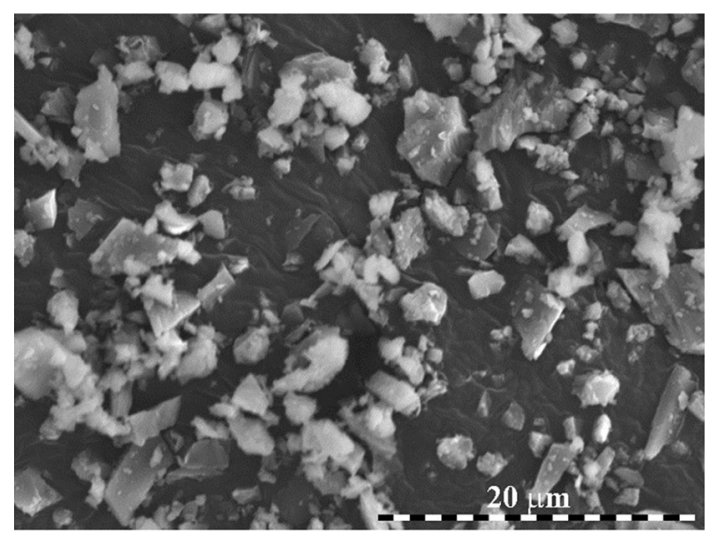

Fig. 1 The SEM image of the utilized waste MD particles chamber. Subsequently, it was sieved until particles in the size range of 5-15 $\mu \mathrm{m}$ were achieved. The PLA and the MD were dried at $80^{\circ} \mathrm{C}$ for $6 \mathrm{~h}$ in a DEGA-2500 type dehumidifier (DE.GA S.p.A., Corte Franca, Italy) prior to compounding. Melt mixing of the PLA-based samples containing 0, 5, 10, 15 and $20 \mathrm{wt} \% \mathrm{MD}$ (designated as PLA, PLA_5MD, PLA_10MD, PLA_15MD and PLA_20MD, respectively) was performed using a LTE 20-44 type twin-screw extruder (Labtech Engineering Co., Ltd., Samut Prakarn, Thailand) with an L/D ratio of 44 and a screw diameter of $20 \mathrm{~mm}$. The screw speed was set to $30 \mathrm{rpm}$. The temperature profile of the extruder (from feed zone to die end) was 155, 160, 160, $165,165,170,170,175,180,185,185^{\circ} \mathrm{C}$. The extruded filaments were then pelletized.

Specimens for the tests were prepared by injection molding using an Allrounder Advance 420C Golden Edition injection molding machine (Arburg, Lossburg, Germany) equipped with a screw of $35 \mathrm{~mm}$ diameter. A melt temperature of $195{ }^{\circ} \mathrm{C}$, an injection rate of $40 \mathrm{~cm}^{3} / \mathrm{s}$, a holding pressure profile of 750-650-250 bar (a total of 15 s), a residual cooling time of $30 \mathrm{~s}$ and a mold temperature of $35^{\circ} \mathrm{C}$ were applied. Prior to the injection molding process the extruded pellets were dried for another $6 \mathrm{~h}$ at $80^{\circ} \mathrm{C}$.

\section{Measurements and Characterization}

The tensile properties of the samples were determined with an Instron 5582 universal testing machine (Instron Ltd., Norwood, USA) equipped with a $10 \mathrm{kN}$ force sensor. The tensile tests were carried using dumbbell-shaped specimens with a cross-section of $10 \mathrm{~mm} \times 4 \mathrm{~mm}$ (according to the EN ISO 527 standard). The crosshead speed was set to $5 \mathrm{~mm} / \mathrm{min}$ $(1 \mathrm{~mm} / \mathrm{min}$ when determining the Young's modulus) and the clamping distance was $100 \mathrm{~mm}$. The results reported are the averages of five parallel measurements carried out at ambient temperature.

Static three-point bending tests were performed on rectangular specimens of $10 \mathrm{~mm} \times 4 \mathrm{~mm}$ according to the EN ISO 178 standard, using the same Instron 5582 universal testing machine that was applied for the tensile tests. This time the crosshead speed was $5 \mathrm{~mm} / \mathrm{min}(1 \mathrm{~mm} / \mathrm{min}$ when determining the flexural modulus). The span length was $64 \mathrm{~mm}$. The results reported are the averages of five parallel measurements carried out at ambient temperature.

Charpy impact tests were performed according to the EN ISO 179 standard on a Ceast 6545 pendulum-type impact tester (Ceast S.p.A., Pianezza, Italy). The specimens were unnotched, rectangular bars $(10 \mathrm{~mm} \times 4 \mathrm{~mm} \times 80 \mathrm{~mm})$. The bearing distance was set to $62 \mathrm{~mm}$ and the impact energy was $2 \mathrm{~J}$. The results reported are the averages of five parallel measurements carried out at ambient temperature.

Experimental density of the manufactured composites was determined using standard water displacement 
technique (Archimedes principle) at room temperature $\left(\sim 25{ }^{\circ} \mathrm{C}\right)$. Void content $(\%)$ in the composites was determined by normalizing the difference of the theoretical and experimental densities with theoretical density, whereas theoretical density was computed using rule of mixture.

The wear performance of the manufactured MD filled composites was analyzed as per ASTM G 99 standard on a pin-on-disc machine (Ducom, India). The schematic and working of the pin-on-disc machine was reported elsewhere [35]. In brief, the sample $(20 \mathrm{~mm} \times 5 \mathrm{~mm} \times 5 \mathrm{~mm})$ was held stationary within the sample holder normal to the disc. Experiments were conducted for the selected control factors of sliding velocity, normal load and sliding distance. The samples were weighed in an electronic balance (Wensar Weighing Scales Ltd., India) before and after wear test. The measured weight loss was then utilized for volumetric wear $\left(\omega_{v}\right)$ calculated with Eq. (1):

$\omega_{v}=\frac{\Delta m}{\rho}$

where $\Delta m$ is the weight loss (g) and $\rho$ is the composite density $\left(\mathrm{g} / \mathrm{cm}^{3}\right)$.

To observe the influence of the marble waste content, sliding distance, sliding velocity and normal load on the volumetric wear of the composites and to obtain the optimum combination of these parameters for achieving minimum wear, the experiments were planned using Taguchi's design of experimental method. The sliding wear tests on the manufactured composites were carried out under different operating conditions considering four control factors each at five levels as MD $(0,5,10$, 15 and $20 \mathrm{wt} \%)$, sliding distance $(400,800,1200,1600$ and $2000 \mathrm{~m}$ ), sliding velocity $(1,2,3,4$ and $5 \mathrm{~m} / \mathrm{s})$ and normal load $(10,20,30,40$ and $50 \mathrm{~N})$ in accordance with $\mathrm{L}_{25}$ orthogonal array of Taguchi's experimental design as listed in Table S1 (supplementary materials) at room temperature. In conventional full factorial experiment design, it would require $5^{4}=625$ runs to study four control factors each at five levels, whereas, Taguchi's approach reduces it to 25 experiments offering a great advantage in terms of experimental cost and time. The results of wear tests obtained through the Taguchi's experimental design are then transformed into signal-to-noise ratio (SNR) using the software Minitab ${ }^{\circledR} 15$. There are three types of SNR, namely bigger-the-better, nominal-the-better and smallerthe-better available for the analysis of the output values. Usually, the best output can be identified by the large value of the SNR as well as the optimum levels of control factors are also identified by the larger SNR regardless of the type of SNR. Since the present study involves the minimization of wear, the SNR for the case of smaller-the-better was selected and evaluated according to Eq. (2):
$S N R=-10 \times \log \frac{1}{\beta}\left(\sum \alpha^{2}\right)$

where $\alpha$ is the volumetric wear and $\beta$ is the number of experiments.

The fractured surfaces and the surfaces exposed to the sliding wear tests were studied by scanning electron microscopy (SEM). For this purpose an S-3400 N (Hitachi, Tokyo, Japan) apparat with an acceleration voltage of $10 \mathrm{kV}$ was used. The surfaces were coated with a gold layer prior to SEM inspection using a Quorum SC7620 type high-vacuum sputter coater (Quorum Technologies Ltd., Laughton, UK).

Differential scanning calorimetric (DSC) measurements were performed in a Setaram DSC 131 evo type calorimeter (Setaram Instrumentation, Caluire-et-Cuire, France). The following procedure was adopted: samples were firstly heated from room temperature to $200{ }^{\circ} \mathrm{C}$ at a scan rate of $5{ }^{\circ} \mathrm{C} / \mathrm{min}$ to erase the thermal history, subsequently they were cooled to $30{ }^{\circ} \mathrm{C}$ at a cooling rate of $5{ }^{\circ} \mathrm{C} / \mathrm{min}$, finally the second heating run took place from 30 to $200^{\circ} \mathrm{C}$, which was also carried out at $5{ }^{\circ} \mathrm{C} / \mathrm{min}$. The experiments were performed in a nitrogen atmosphere. Samples of about $5 \mathrm{mg}$ were used for the test. Based on the DSC traces the glass transition temperature $\left(T_{g}\right)$, the temperature related to the maximum cold crystallization rate $\left(T_{c c}\right)$, the temperature related to the maximum melting rate $\left(T_{m}\right)$, the crystallization enthalpy $\left(\Delta H_{c c}\right)$ and the melting enthalpy $\left(\Delta H_{m}\right)$ were determined. The rate of crystallinity $\left(X_{c}\right)$ was then calculated from the second heating scan using Eq. (3):

$x_{c}=\frac{\Delta H_{m P L A}}{\Delta H_{m P L A}^{\infty} \times \omega_{P L A}}$

where $\Delta H_{m P L A}(\mathrm{~J} / \mathrm{g})$ is the apparent melting enthalpy of PLA, $\Delta H^{\infty}{ }_{m P L A}(\mathrm{~J} / \mathrm{g})$ is the melting enthalpy for $100 \%$ crystalline PLA and $\omega_{P L A}$ is the weight fraction of PLA in the corresponding composite. The degree of crystallinity was calculated considering an ideal melting enthalpy $\left(\Delta H^{\infty}{ }_{m P L A}\right)$ of $93 \mathrm{~J} / \mathrm{g}[36]$.

The obtained results were evaluated using the one-way analysis of variance (ANOVA) method followed by the Tukey-Kramer comparison tests at the significance level of $5 \%(p<0.05)$.

\section{Results and Discussion}

\section{Tensile Mechanical Properties}

The tensile mechanical properties of neat PLA and its composites filled with various amounts of MD are presented in Table 1. The presence of marble particles obviously influenced the mechanical behavior of the 
Table 1 Tensile mechanical properties of the PLA/MD samples containing 0-20 wt\% MD

\begin{tabular}{lllll}
\hline Sample & $\begin{array}{l}\text { Ultimate tensile strength } \\
(\mathrm{MPa})\end{array}$ & Young's modulus $(\mathrm{GPa})$ & Elongation at yield (\%) & Elongation at break (\%) \\
\hline PLA & $57.9 \pm 0.3^{\mathrm{a}}$ & $2.56 \pm 0.04^{\mathrm{a}}$ & $2.95 \pm 0.15^{\mathrm{a}}$ & $5.22 \pm 0.76^{\mathrm{a}}$ \\
PLA_5MD & $53.8 \pm 0.6^{\mathrm{b}}$ & $2.73 \pm 0.04^{\mathrm{b}}$ & $2.49 \pm 0.06^{\mathrm{b}}$ & $3.23 \pm 0.28^{\mathrm{b}}$ \\
PLA_10MD & $53.1 \pm 0.7^{\mathrm{b}}$ & $2.89 \pm 0.04^{\mathrm{c}}$ & $2.34 \pm 0.07^{\mathrm{b}}$ & $2.87 \pm 0.77^{\mathrm{b}}$ \\
PLA_15MD & $52.3 \pm 0.1^{\mathrm{b}, \mathrm{c}}$ & $3.07 \pm 0.04^{\mathrm{d}}$ & $2.30 \pm 0.07^{\mathrm{b}, \mathrm{c}}$ & $2.37 \pm 0.05^{\mathrm{b}}$ \\
PLA_20MD & $50.1 \pm 1.0^{\mathrm{c}}$ & $3.23 \pm 0.06^{\mathrm{e}}$ & $2.07 \pm 0.04^{\mathrm{c}}$ & $2.10 \pm 0.01^{\mathrm{b}}$ \\
\hline
\end{tabular}

Mean \pm standard deviation. Same superscript letters within the same column are not significantly different at $5 \%$ significance level according to the ANOVA and Tukey-Kramer test

polymer matrix. In general, ultimate tensile strength values decreased slightly in the presence of MD. The addition of $5 \mathrm{wt} \% \mathrm{MD}$ caused a relative decrease of $7 \%$ in strength compared to neat PLA and at higher filler loading a further 1, 2 and 3\% decrease was observed (for samples PLA_10MD, PLA_15MD and PLA_20 MD, respectively). The presence of inorganic fillers with a size above $\sim 100 \mathrm{~nm}$ tend to reduce the strength of the corresponding composites $[37,38]$ as a result of the inadequate interfacial adhesion of the components and the agglomeration of the particles. In this current case this reduction is at an acceptable level, the composite with the highest filler concentration $(20 \mathrm{wt} \%)$ showed a relative reduction of only $\sim 13.5 \%$, thereby still exhibiting a yield strength higher than $50 \mathrm{MPa}$. With respect to elastic modulus all the PLA/MD composites outperformed the neat PLA sample. A significant linear increment can be observed in the modulus with increasing filler loading, reaching a relative improvement of $\sim 26 \%$ for composites containing $20 \mathrm{wt} \%$ marble powder. This phenomenon is usually attributed to the formation of rigid interfaces within the polymer matrix in the presence of small-sized mineral additives of high stiffness [39], which is in this case the marble. The elongation at yield and the elongation at break values of PLA (2.95\% and $5.22 \%$, respectively) both steadily declined as a function of MD-content, bottoming at $2.07 \%$ and $2.10 \%$, respectively.

The typical tensile curves of PLA and its composites are shown in Fig. 2. It can be observed that the higher the filler content, the less deformation the samples can endure past the yield point. This is most likely due to the poor plasticity of the MD particles. For the composites with MD content higher than $10 \mathrm{wt} \%$ no yielding was observed anymore. Instead, a sudden fracture occurred right after the highest stress measured. This refers to a reduced ductility of the composites, which can also be explained by the presence of marble particles with irregular shapes acting as stress concentrators and thereby leading to an earlier failure during uniaxial stretching.

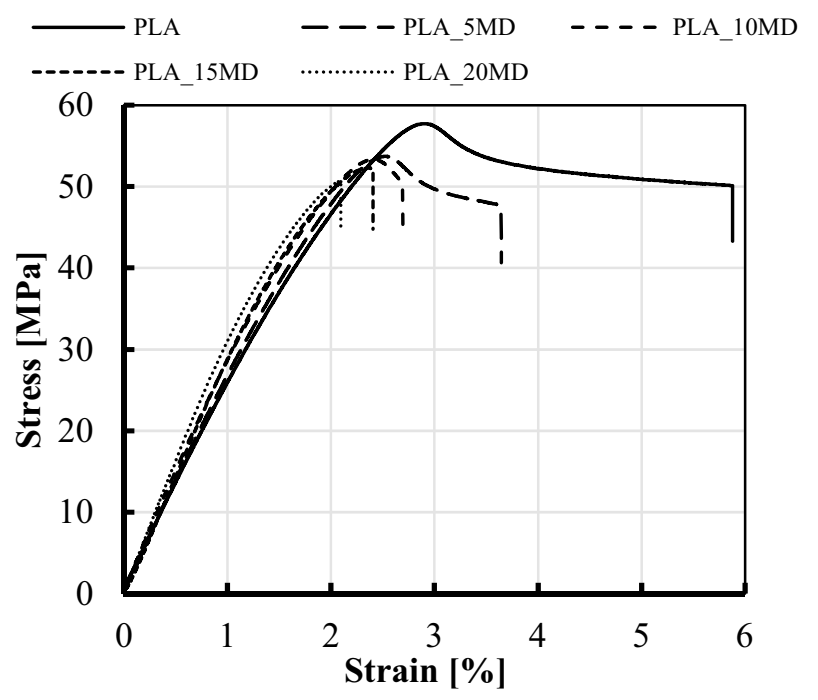

Fig. 2 Typical tensile curves of the PLA/MD samples containing 0-20 wt\% MD

\section{Flexural Mechanical Properties}

The flexural mechanical properties of neat PLA and its MD-filled composites are gathered in Table 2, while Fig. 3 shows typical flexural curves of the examined samples. The flexural stress at conventional deflection measured on neat PLA (99.5 MPa) showed an increase up until $10 \mathrm{wt} \% \mathrm{MD}$ content. After exhibiting the highest value of 102.1 MPa the flexural stress at conventional deflection dropped with further filler loading. A possible explanation for this phenomenon can be the agglomeration of the MD particles, which leads to the reduction of interphase contact surface between the polymer matrix and the marble. It can be concluded that the flexural strength of PLA can be enhanced to some extent if the proper amount is introduced into the system. A similar trend was observed in other studies conducted with different matrices (PP, epoxy). However, in those cases the strength values peaked at higher MD content [22, 23], which was probably due to the better interfacial adhesion between 
Table 2 Flexural properties of the PLA/MD samples containing 0-20 wt\% MD

\begin{tabular}{lcl}
\hline Sample & $\begin{array}{l}\text { Flexural stress at conven- } \\
\text { tional deflection }(\mathrm{MPa})\end{array}$ & Flexural modulus $(\mathrm{GPa})$ \\
\hline PLA & $99.5 \pm 0.2^{\mathrm{a}}$ & $3.43 \pm 0.02^{\mathrm{a}}$ \\
PLA_5MD & $99.7 \pm 2.3^{\mathrm{a}}$ & $3.50 \pm 0.09^{\mathrm{a}}$ \\
PLA_10MD & $102.1 \pm 0.9^{\mathrm{a}}$ & $3.83 \pm 0.07^{\mathrm{b}}$ \\
PLA_15MD & $90.0 \pm 1.0^{\mathrm{b}}$ & $3.98 \pm 0.04^{\mathrm{c}}$ \\
PLA_20MD & $98.5 \pm 0.4^{*}$ & $4.39 \pm 0.08^{\mathrm{d}}$ \\
\hline
\end{tabular}

Mean \pm standard deviation. Same superscript letters within the same column are not significantly different at $5 \%$ significance level according to the ANOVA and Tukey-Kramer test

* Means flexural strength values instead of flexural stress at conventional deflection are given, as the specimens broke before reaching the conventional deflection

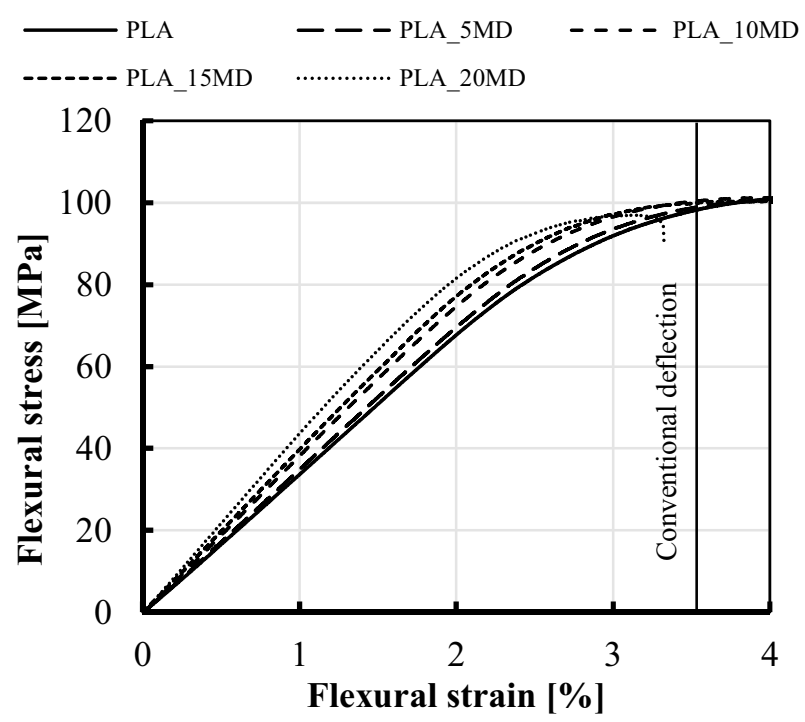

Fig. 3 Typical flexural curves of the PLA/MD samples containing 0-20 wt $\%$ MD

the MD and the applied polymer matrix. As it can be seen in Fig. 3, the deformation of the sample with the maximum MD loading ( $20 \mathrm{wt} \%$ ) did not reach the conventional deflection due to its high level of embrittlement. Therefore, according to the EN ISO 178 standard, flexural strength should be determined instead of the flexural stress at conventional deflection, which was $98.5 \mathrm{MPa}$. The flexural modulus exhibited a steady improvement with increasing MD content reaching a relative increment of 28\% for the sample PLA_20MD (4.39 GPa) compared to that of neat PLA (3.43 GPa). This is in good agreement with the literature [23] and with the tensile tests results as well.

\section{Impact Strength}

The dynamic mechanical properties deduced from the Charpy impact tests are visualized in Fig. 4. PLA is considered as a brittle polymer, with its impact strength of $15.25 \mathrm{~kJ} / \mathrm{m}^{2}$ (measured on unnotched specimen). The toughness of neat PLA enhanced with the increasing weight percentage of MD particles up to $10 \mathrm{wt} \%$, reaching a maximum of $20.88 \mathrm{~kJ} / \mathrm{m}^{2}$. This kind of improvement in fracture toughness in composites with rigid filler particles is generally explained by crack deflection around the filler particulates and the dissipation of energy in the damage zone [38]. There is a considerable drop in impact strength beyond $10 \mathrm{wt} \%$ MD concentration, even though the measured values are still higher than those of neat PLA. This is most probably due to the decreasing inter-particle distance, which below a critical value mostly leads to the embrittlement in particulatecomposites [40]. Besides, the agglomeration of MD particles can also have such an effect. These findings are in good agreement with the tensile tests results that showed a sudden fracture right after reaching the point of ultimate tensile stress for samples with MD content above $10 \mathrm{wt} \%$. Also, the strength measured throughout the flexural tests showed a similar tendency.

\section{Morphology}

SEM observations were performed on the prepared samples in order to determine the dispersion of the MD

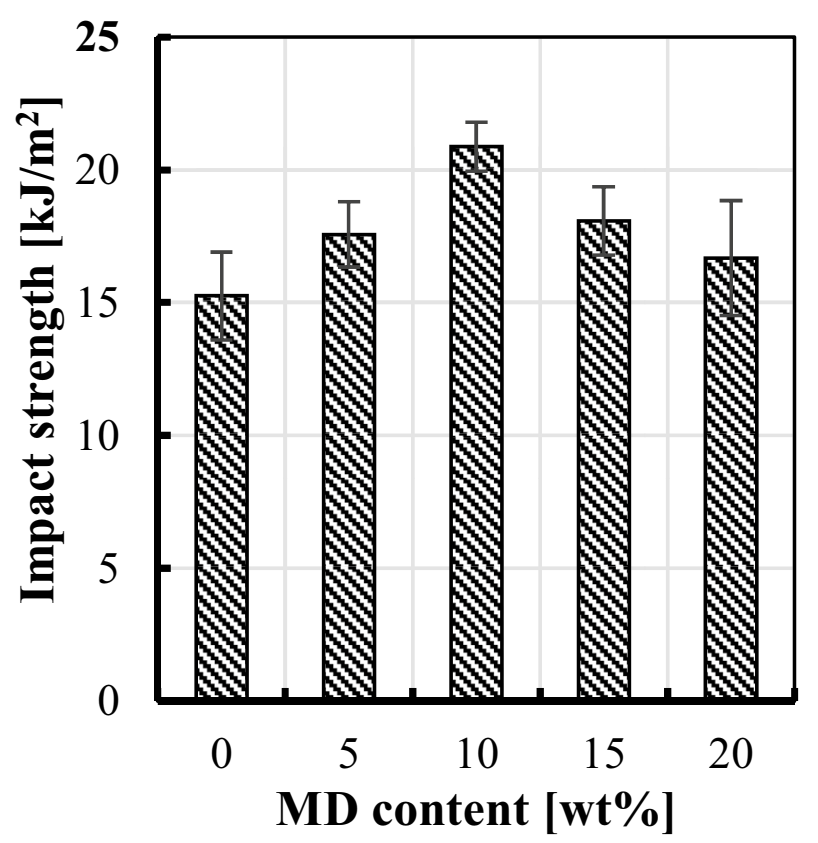

Fig. 4 Charpy impact strength of the neat PLA and the PLA/MD composites 
particles within the PLA matrix. Figure 5 shows the fractured surfaces of samples PLA, PLA_10MD and PLA_20MD, respectively. Figure 5a reveals a quite rigid fracture surface, which is typical for PLA [30, 41]. The characteristics of the surface did not change, even when the MD was incorporated. It can be seen in Fig. 5b that the marble particles got dispersed uniformly throughout the melt mixing in the polymer matrix with a few remaining agglomerates. Based on Fig. $5 \mathrm{c}$ it can be concluded that this fine dispersion is preserved even at higher $(20 \mathrm{wt} \%)$ filler loading. Also, the high number of well-dispersed MD particulates observed on the surface PLA_20MD justifies the conclusions made in 3.3 (Impact strength) that the inter-particle distance considerably decreased, which then led to the decreasing ductility.

\section{Density and Void Content}

The results of theoretical and experimental densities as depicted in Fig. 6 were fluctuated in a small range from 1.24 to $1.39 \mathrm{~g} / \mathrm{cm}^{3}$. The bare PLA sample had the smallest value of density while the density of PLA_20MD composite was the highest, demonstrating that the density increases with the rise of MD concentration. Void content of the composite was found to increase with increased MD loading. This increase in void content may be ascribed to the agglomeration of MD at higher concentration which leads to an increased void content of the composites.

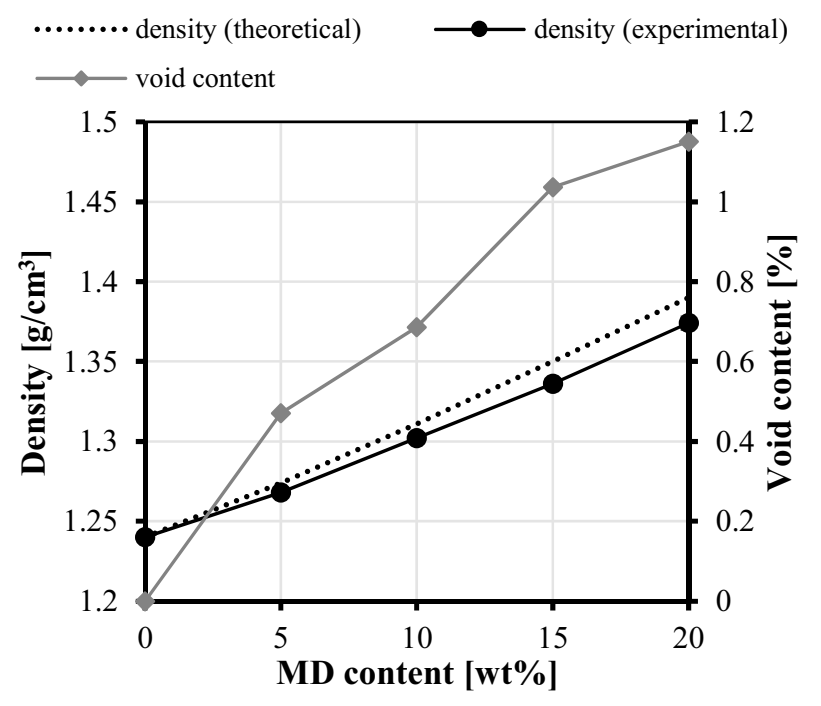

Fig. 6 Density and void content of the manufactured composites

\section{Sliding Wear Analysis}

The sliding wear performance of the manufactured composites was analyzed using Taguchi technique and the significant control factors affecting composite wear were identified. The wear experiments as per the $\mathrm{L}_{25}$ orthogonal array were conducted to examine the influence of four control factors and their five levels on the volumetric wear of the composites. The volumetric wear results for various combinations
Fig. 5 SEM images of the fracture surfaces of PLA (a), PLA_10MD (b) and PLA_20MD (c)
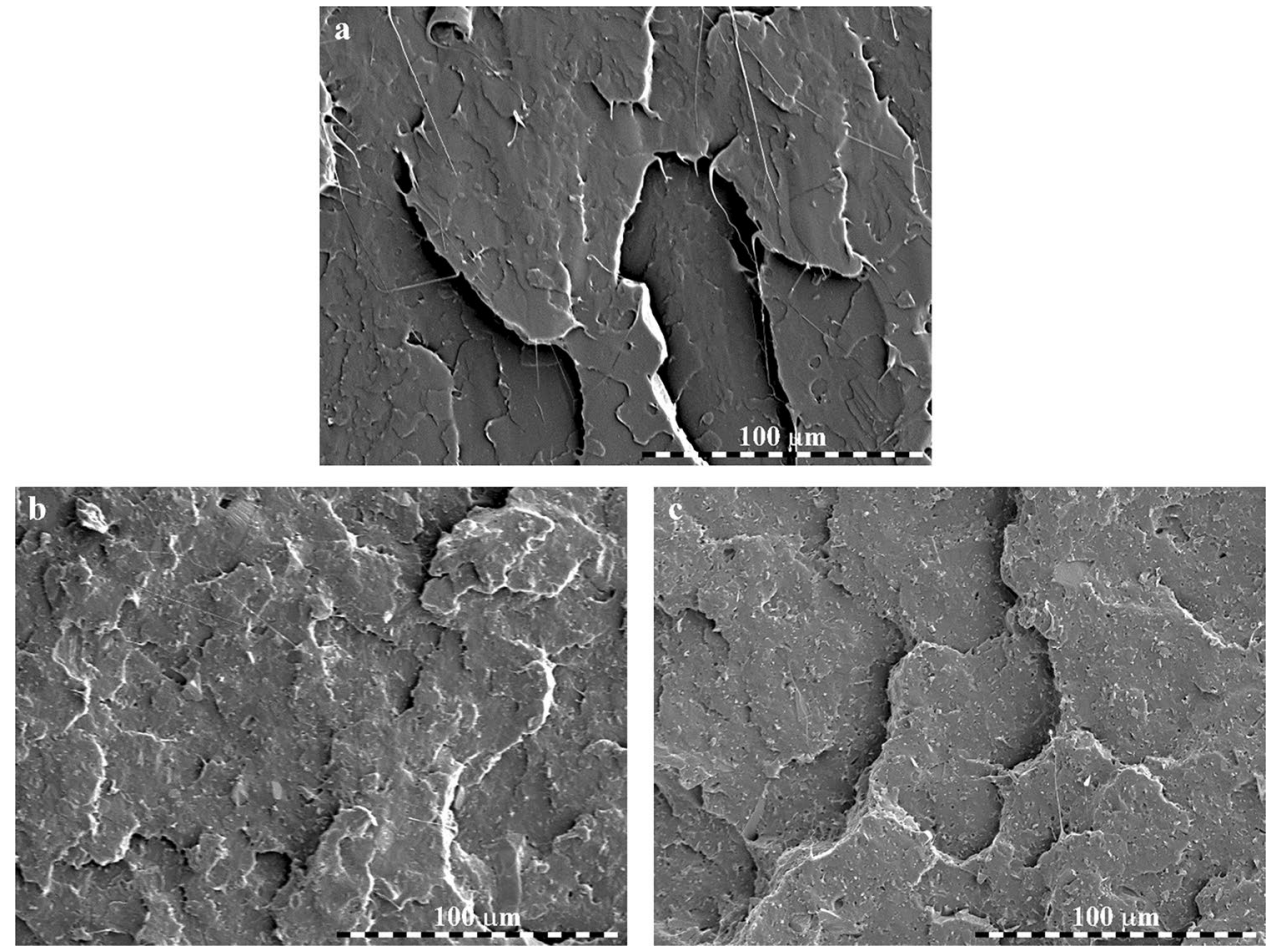
of control factors and their corresponding SNR is presented in Table S2 (supplementary materials). The SNR responses are given in Table 3, from which it can be concluded that among all the factors, normal load is the most significant one followed by sliding velocity, sliding distance and MD content. Moreover a gradual increase in volumetric wear was observed with increase in sliding distance, sliding velocity and normal load. Similar results for wear rate were reported by others [42-44] for PLA composites where wear rate was found to increase with increased normal load. Moreover, authors reported that wear behavior of the manufactured PLA composites was remained more sensitive to load variation than the sliding velocity variations. In the meanwhile, the volumetric wear first increased with MD content from 0 to $15 \mathrm{wt} \%$ and then observed to decrease with $20 \mathrm{wt} \%$ MD. Analysis of these results leads to the conclusion that combination of factors A4 (20 wt \% MD), B1 (400 m sliding distance), $\mathrm{C} 1$ ( $1 \mathrm{~m} / \mathrm{s}$ sliding velocity) and D1 (10 N normal load) gives minimum volumetric wear. Similar observations have been reported by various researchers in regard to the effect of MD as filler on the wear performance of polymer composites $[45,46]$. Authors claimed that wear resistance was remained highest with the combination of lower sliding distance, sliding velocity, normal load with higher MD filled polymer composites.

The surface morphologies for wear-tested neat PLA and MD filled PLA composites are presented in Fig. 7a-e, respectively. The worn surface of neat PLA (Fig. 7a) sliding for $400 \mathrm{~m}$ distance at $10 \mathrm{~N}$ load and $1 \mathrm{~m} / \mathrm{s}$ velocity [test run 1 within Table S1 (supplementary materials)] was characterized by smooth surface, along with small grooves due to micro-ploughing and peeling-off matrix material was also observed, all suggesting mild wear [43, 47, 48]. With the inclusion of MD (5-15 wt\%, Fig. 7b-d), the worn surfaces appeared rough and characterized by severe deformation. The worn surface of PLA_5MD composite (Fig. 7b) sliding for $1200 \mathrm{~m}$ distance at $50 \mathrm{~N}$ load with $4 \mathrm{~m} / \mathrm{s}$ sliding velocity [test run 8 within Table S1 (supplementary materials)] experienced scuffing and peeling-off material due to melting of matrix with increased interfacial temperature. This observation indicated increased wear due to the dominant

Table 3 Response table for signal to noise ratios of volumetric wear

\begin{tabular}{lllll}
\hline Level & A & B & C & D \\
\hline 1 & 21.06 & 22.03 & 24.56 & 25.30 \\
2 & 19.39 & 19.70 & 21.54 & 19.31 \\
3 & 17.59 & 19.16 & 16.54 & 19.03 \\
4 & 16.35 & 17.06 & 16.64 & 16.10 \\
5 & 21.30 & 17.75 & 16.43 & 15.96 \\
Delta & 4.95 & 4.98 & 8.13 & 9.34 \\
Rank & 4 & 3 & 2 & 1 \\
\hline
\end{tabular}

mechanism of adhesion. The worn surfaces of sample PLA_10MD [Fig. 7c, sliding for $2000 \mathrm{~m}$ distance at $40 \mathrm{~N}$ load with $2 \mathrm{~m} / \mathrm{s}$ sliding velocity; test run 15 within Table $\mathrm{S} 1$ (supplementary materials)] and PLA_15MD [Fig. 7d, sliding for $1600 \mathrm{~m}$ distance at $50 \mathrm{~N}$ load with $2 \mathrm{~m} / \mathrm{s}$ sliding velocity; test run 19 within Table S1 (supplementary materials)] composites appeared more rough with higher deformation. Scuffing and peeling-off material was also observed on the worn surfaces which resulted in reduced wear resistance of the composites. Moreover, the MD filled composites were observed to have pit formation due to the pull-out of MD particles during sliding. These pulled-out MD particles abrade the composite surfaces, in addition they contribute to the increased wear due to abrasion mechanism. The worn surface of PLA_20MD (Fig. 7e) composite sliding for $2000 \mathrm{~m}$ distance at $30 \mathrm{~N}$ load with $4 \mathrm{~m} / \mathrm{s}$ sliding velocity [test run 25 within Table S1 (supplementary materials)] was comparatively smoother and witnessed no obvious materials peeling-off and scuffing phenomena, therefore they contributed to decreased wear of such composite. The reduced wear for PLA_20MD composite may be ascribed that the filler covers maximum region and bear the maximum load during sliding which protect the matrix from scuffing and peelingoff and resulted in reduced wear of the composite [49-51].

\section{DSC Characteristics}

The results obtained from the DSC measurements are collected in Table 4. Each sample showed three thermal transitions in total throughout the heating process. These are the glass transition, the cold crystallization and the melting, respectively. As it can be observed in Fig. 8, all the samples exhibited two partially overlapping melting peaks, regardless of MD content. The presence of these double melting peaks are generally attributed to the differences in crystalline morphology. In the literature these crystalline variations of PLA are denoted as $\alpha$ and $\alpha^{\prime}$, where $\alpha^{\prime}$ is a metaphase having a looser packing manner and lower density than the more ordered, stable $\alpha$ crystalline form [52,53]. When comparing the DSC curves of the different samples only marginal differences can be noticed. A slight, but consistent increment was observed in the $T_{g}$ of the MD containing composites with respect to unfilled PLA $\left(61.4{ }^{\circ} \mathrm{C}\right)$, indicating a restricted mobility of chain molecules induced by the embedded marble particles. The cold crystallization peak shifted to lower temperatures in the presence MD. The $T_{c c}$ measured on the PLA control sample $\left(110.4{ }^{\circ} \mathrm{C}\right)$ constantly decreased with increasing MD loading, bottoming at $106.9^{\circ} \mathrm{C}$ when $20 \mathrm{wt} \%$ $\mathrm{MD}$ was incorporated. The temperature range of cold crystallization is generally affected by two factors: (i) the rate of nucleation and ii) the mobility of chain molecules [54]. As increased chain mobility is not justified considering the $T_{g}$ values, it can be assumed that the MD particles had a 
Fig. 7 SEM images taken from surfaces exposed to wear of samples PLA (a), PLA_5MD (b), PLA_10MD (c), PLA_15MD (d) and PLA_20MD (e)
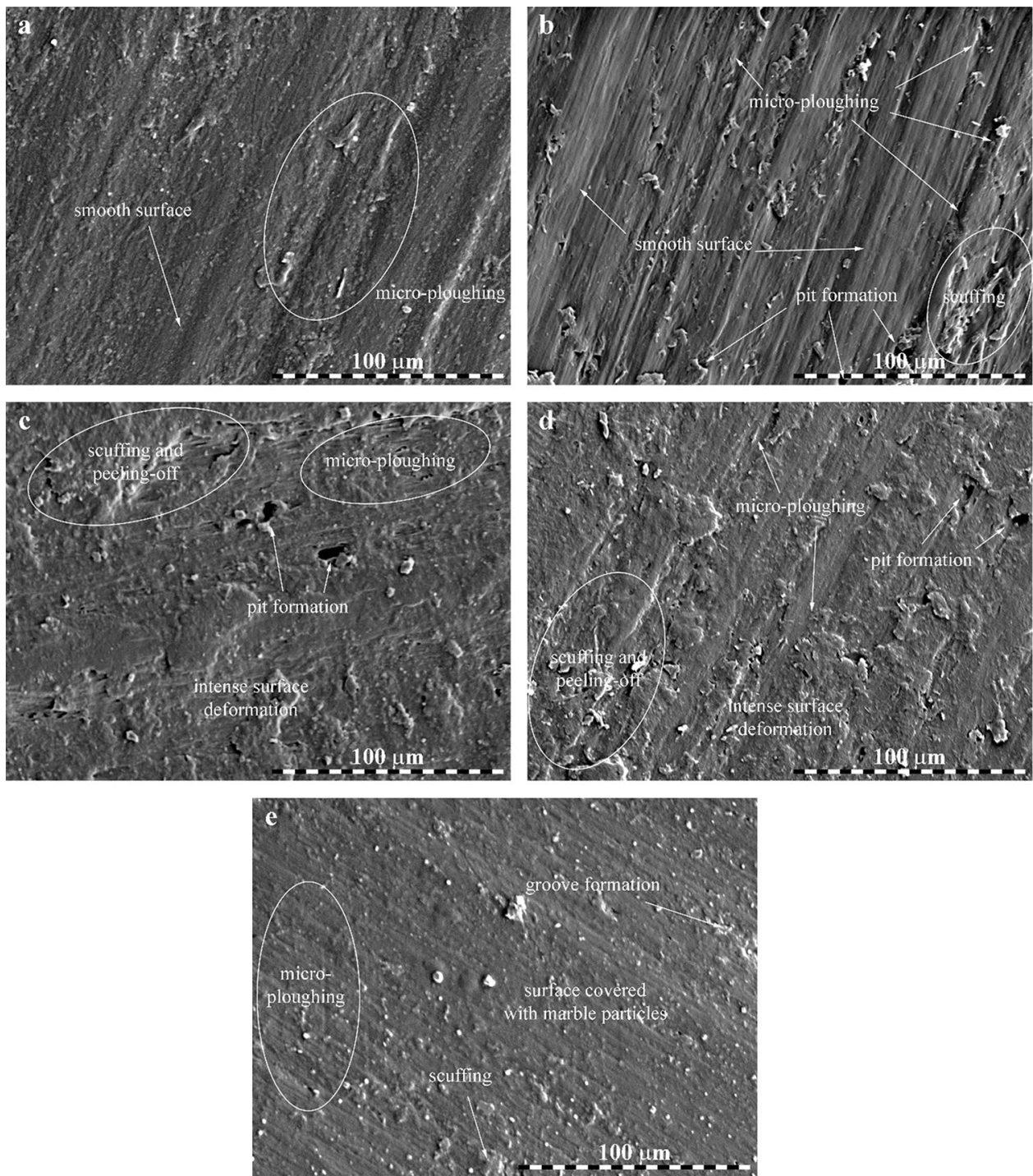

\begin{tabular}{llllllll}
\hline Sample & $T_{g}\left({ }^{\circ} \mathrm{C}\right)$ & $T_{c c}\left({ }^{\circ} \mathrm{C}\right)$ & $\Delta H_{c c}(\mathrm{~J} / \mathrm{g})$ & $T_{m l}\left({ }^{\circ} \mathrm{C}\right)$ & $T_{m 2}\left({ }^{\circ} \mathrm{C}\right)$ & $\Delta H_{m}(\mathrm{~J} / \mathrm{g})$ & $X_{c}(\%)$ \\
\hline PLA & 61.4 & 110.4 & 26.5 & 150.8 & 157.2 & 26.6 & 28.6 \\
PLA_5MD & 61.6 & 110.4 & 21.8 & 150.7 & 156.0 & 21.9 & 24.8 \\
PLA_10MD & 62.7 & 109.7 & 20.0 & 150.6 & 156.1 & 20.1 & 24.0 \\
PLA_15MD & 62.7 & 108.5 & 21.4 & 150.4 & 156.3 & 21.6 & 27.3 \\
PLA_20MD & 62.4 & 106.9 & 19.9 & 150.1 & 156.2 & 20.2 & 27.2 \\
\hline
\end{tabular}

nucleating effect on the PLA matrix. Regarding the melting temperatures it can be concluded that neither the $T_{m l}$, nor the $T_{m 2}$ of PLA $\left(150.8{ }^{\circ} \mathrm{C}\right.$ and $157.2^{\circ} \mathrm{C}$, respectively) was affected by the incorporated marble powder. In the meanwhile, with higher MD content the second melting peak became more prominent, while the size of the first melting peak decreased. Apparently, the embedded MD particulates favored the formation of the more stable $\alpha$ crystalline structure. The melting enthalpy $\left(\Delta H_{m}\right)$ of all samples roughly equaled the enthalpy of their cold crystallization $\left(\Delta H_{c c}\right)$, which indicates that the samples were amorphous prior to the heating sequence. This is supported by the fact that no crystallization phenomenon (no exothermic peak) was observed throughout the cooling run. The rate of crystallinity $\left(X_{c}\right)$ decreased in the presence of 5-10 wt\% MD by $\sim 4 \%$, compared to neat PLA (28.6\%). However, at higher filler concentration a growth in $X_{c}$ was observed, reaching $27.3 \%$ and $27.2 \%$ (for the samples PLA_MD15 and PLA_MD20, 


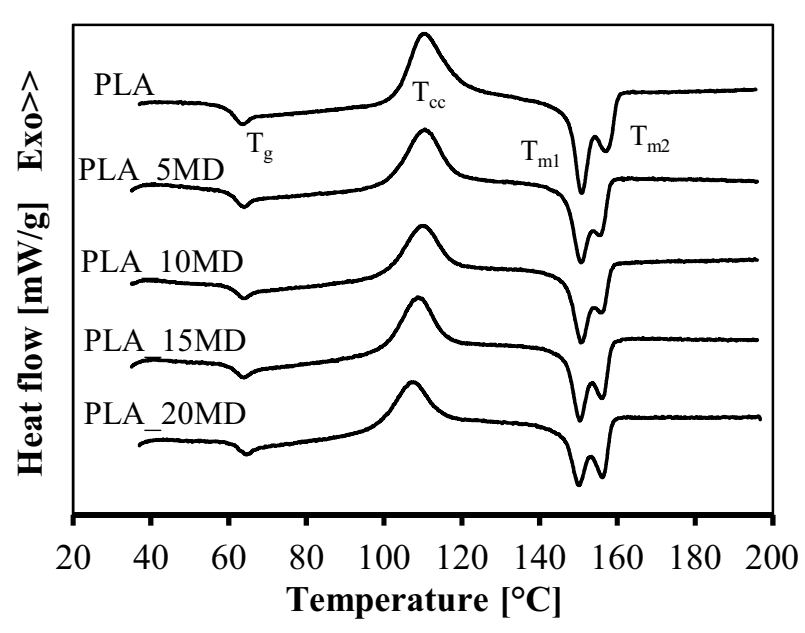

Fig. 8 Characteristic DSC curves obtained throughout the second heating of PLA and its MD-filled composites

respectively). These findings further support the assumptions made earlier, namely: (i) as the MD hampers the chain motions, the arrangement of chain molecules into crystalline structures during the cold crystallization is hindered, which explains the generally lower crystallinity of the composites; (ii) in the meanwhile, the marble particles also act as nucleating agents in the polymer, leading to higher crystalline ratios with increased MD content. Note, that the calculated $X_{c}$ values are crystalline ratios that can only be applied in the temperature range, where the cold crystallization is already finished, but the melting of the samples did not yet begin, otherwise, both the unfilled PLA and the composites exhibited an amorphous structure.

\section{Conclusion}

Nowadays, there is an increasing amount of waste dust generated throughout the cutting process of marble bricks. Since there is no general solution for the handling of MD, it raises serious environmental concerns. Finding suitable applications for the dust is a major challenge.

In this study the applicability of MD was investigated as filler in polymer composites. Due to environmental considerations a biopolymer, the PLA was chosen as matrix. Common thermoplastic techniques, namely extrusion and injection molding were applied to prepare suitable specimens for the characterization of the composites. According to the SEM images, the applied processing techniques led to a fine dispersion of marble particulates within the PLA matrix. A constantly increasing stiffness was observed both during the tensile and the flexural tests with increasing MD concentration. Even though the ultimate tensile strength of PLA was lower in the presence of marble, the reduction is at an acceptable level, since even the composite containing the highest amount ( $20 \mathrm{wt} \%$ ) of MD still exhibited a tensile strength higher than $50 \mathrm{MPa}$. The values of flexural strength and impact strength increased up until $10 \mathrm{wt} \%$ filler loading, however, above this concentration a decrease occurred due to embrittlement. The crystallization kinetics of PLA altered to some extent leading to a slightly higher $T_{g}$ and $T_{c c}$ temperatures and lower crystallinity due to the MD hampering the chain motions of the polymer. The sliding wear analysis revealed that $20 \mathrm{wt} \%$ MD filled composites resulted as the most wear resistant materials.

Based on the results it can be assumed that the incorporation of MD into the PLA has high relevancy for industrial use. Most of the properties analyzed throughout this study either improved or only dropped slightly. Accordingly, the advantage of utilizing MD in PLA-based composites is threefold. Firstly, as a considerable amount of PLA can be replaced by MD—which is essentially for free- the costs of the biopolymer can be decreased significantly, which could help its worldwide spread. Secondly, the environmental issues caused by the dumped waste MD could be mitigated. And thirdly, the increased properties of PLA achieved by the incorporation of marble particulates might increase its possible fields of application.

Supplementary Information The online version contains supplementary material available at https://doi.org/10.1007/s10924-021-02091-9.

Acknowledgement The research was carried in the framework of the New Széchenyi Plan (Grant No. EFOP-3.6.2-16-2017-00016). This project is funded by the European Union and co-financed by the European Social Fund.

Funding Open access funding provided by Széchenyi István University (SZE).

Open Access This article is licensed under a Creative Commons Attribution 4.0 International License, which permits use, sharing, adaptation, distribution and reproduction in any medium or format, as long as you give appropriate credit to the original author(s) and the source, provide a link to the Creative Commons licence, and indicate if changes were made. The images or other third party material in this article are included in the article's Creative Commons licence, unless indicated otherwise in a credit line to the material. If material is not included in the article's Creative Commons licence and your intended use is not permitted by statutory regulation or exceeds the permitted use, you will need to obtain permission directly from the copyright holder. To view a copy of this licence, visit http://creativecommons.org/licenses/by/4.0/.

\section{References}

1. Siracusa V, Rocculi P, Romani S, Rosa MD (2008) Biodegradable polymers for food packaging: a review. Trends Food Sci Technol 19:634-643

2. Pathak VM, Navneet (2017) Review on the current status of polymer degradation: a microbial approach. Bioresour Bioprocess 4:15 
3. Dogossy G, Czigany T (2011) Thermoplastic starch composites reinforced by agricultural by-products: properties, biodegradability, and application. J Reinf Plast Compos 30:1819-1825

4. Molins G, Álvarez MD, Garrido N, Macanás J, Carrillo F (2018) Environmental impact assessment of polylactide (PLA)/chicken feathers biocomposite materials. J Polym Environ 26:873-884

5. Väntsi O, Kärki T (2015) Environmental assessment of recycled mineral wool and polypropylene utilized in wood polymer composites. Resour Conserv Recycl 104:38-48

6. Van De Sande J, Peys A, Hertel T, Rahier H, Pontikes Y (2020) Upcycling of non-ferrous metallurgy slags: identifying the most reactive slag for inorganic polymer construction materials. Resour Conserv Recycl 154:104627

7. Clark E, Bleszynski M, Valdez F, Kumosa M (2020) Recycling carbon and glass fiber polymer matrix composite waste into cementitious materials. Resour Conserv Recycl 155:104659

8. Kore SD, Vyas AK (2016) Impact of marble waste as coarse aggregate on properties of lean cement concrete. Case Stud Constr Mater 4:85-92

9. Pappu A, Thakur VK, Patidar R, Asolekar SR, Saxena M (2019) Recycling marble wastes and jarosite wastes into sustainable hybrid composite materials and validation through response surface methodology. J Clean Prod 240:118249

10. Awad AH, Abdellatif MH (2019) Assessment of mechanical and physical properties of LDPE reinforced with marble dust. Composites B 173:106948

11. Rana A, Kalla P, Csetenyi LJ (2015) Sustainable use of marble slurry in concrete. J Clean Prod 94:304-311

12. Çınar ME, Kar F (2018) Characterization of composite produced from waste PET and marble dust. Constr Build Mater 163:734-741

13. Yavuz Çelik M, Sabah E (2008) Geological and technical characterisation of Iscehisar (Afyon-Turkey) marble deposits and the impact of marble waste on environmental pollution. J Environ Manage 87:106-116

14. Thakur AK, Pappu A, Thakur VK (2018) Resource efficiency impact on marble waste recycling towards sustainable green construction materials. Curr Opin Gr Sustain Chem 13:91-101

15. Aruntaş HY, Gürü M, Dayı M, Tekin İ (2010) Utilization of waste marble dust as an additive in cement production. Mater Des 31:4039-4042

16. Nasserdine K, Mimi Z, Bevan B, Elian B (2009) Environmental management of the stone cutting industry. J Environ Manage 90:466-470

17. Fahiminia M, Ardani R, Hashemi S, Alizadeh M (2013) Wastewater treatment of stone cutting industries by coagulation process. Arch Hyg Sci 2:16-22

18. Soydal U, Kocaman S, Esen Marti M, Ahmetli G (2018) Study on the reuse of marble and andesite wastes in epoxy-based composites. Polym Compos 39:3081-3091

19. Fiore V, Di Bella G, Scalici T, Valenza A (2018) Effect of plasma treatment on mechanical and thermal properties of marble powder/epoxy composites. Polym Compos 39:309-317

20. Gürü M, Tekeli S, Akin E (2007) Manufacturing of polymer matrix composite material using marble dust and fly ash. Key Eng Mater 336-338:1353-1356

21. Choudhary M, Singh T, Dwivedi M, Patnaik A (2019) Waste marble dust-filled glass fiber-reinforced polymer composite Part I: physical, thermomechanical, and erosive wear properties. Polym Compos 40:4113-4124

22. Choudhary M, Singh T, Sharma A, Dwivedi M, Patnaik A (2019) Evaluation of some mechanical characterization and optimization of waste marble dust filled glass fiber reinforced polymer composite. Mater Res Express 6:105702
23. Awad AH, El-gamasy R, El-Wahab AAA, Abdellatif MH (2019) Mechanical behavior of PP reinforced with marble dust. Constr Build Mater 228:116766

24. Beigbeder J, Soccalingame L, Perrin D, Bénézet J-C, Bergeret A (2019) How to manage biocomposites wastes end of life? A life cycle assessment approach (LCA) focused on polypropylene (PP)/ wood flour and polylactic acid (PLA)/flax fibres biocomposites. Waste Manage 83:184-193

25. Nakagaito AN, Fujimura A, Sakai T, Hama Y, Yano H (2009) Production of microfibrillated cellulose (MFC)-reinforced polylactic acid (PLA) nanocomposites from sheets obtained by a papermaking-like process. Compos Sci Technol 69:1293-1297

26. Garlotta D (2001) A literature review of poly(lactic acid). J Polym Environ 9:63-84

27. Madhavan Nampoothiri K, Nair NR, John RP (2010) An overview of the recent developments in polylactide (PLA) research. Bioresour Technol 101:8493-8501

28. Herrera N, Mathew AP, Oksman K (2015) Plasticized polylactic acid/cellulose nanocomposites prepared using melt-extrusion and liquid feeding: mechanical, thermal and optical properties. Compos Sci Technol 106:149-155

29. Muller J, Gonzalez-Martinez C, Chiralt A (2017) Combination of poly(lactic) acid and starch for biodegradable food packaging. Materials 10:952

30. Lendvai L, Brenn D (2020) Mechanical, morphological and thermal characterization of compatibilized poly(lactic acid)/thermoplastic starch blends. Acta Technica Jaurinensis 13:1-13

31. Hajba S, Tábi T (2018) Investigation of long cellulose fibre reinforced and injection moulded poly(lactic acid) biocomposites. Acta Technica Jaurinensis 11:150-164

32. Totaro G, Sisti L, Fiorini M, Lancellotti I, Andreola FN, Saccani A (2019) Formulation of green particulate composites from PLA and PBS matrix and wastes deriving from the coffee production. J Polym Environ 27:1488-1496

33. Lendvai L, Fekete I (2020) Preparation and characterization of poly(lactic acid)/boehmite alumina composites for additive manufacturing. IOP Conf Ser Mater Sci Eng 903:012057

34. Kmetty A, Litauszki K, Reti D (2018) Characterization of different chemical blowing agents and their applicability to produce poly(lactic acid) foams by extrusion. Appl Sci 8:1960

35. Singh T, Gangil B, Singh B, Verma SK, Biswas D, Fekete G (2019) Natural-synthetic fiber reinforced homogeneous and functionally graded vinylester composites: effect of Bagasse-Kevlar hybridization on wear behavior. J Mater Res Technol 8:5961-5971

36. Battegazzore D, Bocchini S, Frache A (2011) Crystallization kinetics of poly(lactic acid)-talc composites. Express Polym Lett 5:849-858

37. Barczewski M, Sałasińska K, Kloziński A, Skórczewska K, Szulc J, Piasecki A (2019) Application of the basalt powder as a filler for polypropylene composites with improved thermo-mechanical stability and reduced flammability. Polym Eng Sci 59:E71-E79

38. Fu S-Y, Feng X-Q, Lauke B, Mai Y-W (2008) Effects of particle size, particle/matrix interface adhesion and particle loading on mechanical properties of particulate-polymer composites. Composites B 39:933-961

39. Pedrazzoli D, Khumalo VM, Karger-Kocsis J, Pegoretti A (2014) Thermal, viscoelastic and mechanical behavior of polypropylene with synthetic boehmite alumina nanoparticles. Polym Test 35:92-100

40. Kausch HH, Michler GH (2007) Effect of nanoparticle size and size-distribution on mechanical behavior of filled amorphous thermoplastic polymers. J Appl Polym Sci 105:2577-2587

41. Correa-Pacheco ZN, Black-Solis JD, Ortega-Gudino P, SabinoGutierrez MA, Benitez-Jimenez JJ, Barajas-Cervantes A, Bautista-Banos S, Hurtado-Colmenares LB (2020) Preparation and 
characterization of bio-based PLA/PBAT and cinnamon essential oil polymer fibers and life-cycle assessment from hydrolytic degradation. Polymers 12:32

42. Bajpai PK, Singh I, Madaan J (2013) Tribological behavior of natural fiber reinforced PLA composites. Wear 297:829-840

43. Kanakannavar S, Pitchaimani J, Ramesh MR (2020) Tribological behaviour of natural fibre 3D braided woven fabric reinforced PLA composites. Proc Inst Mech Eng J. https://doi.org/10.1177/13506 50120954949

44. Kumar AAJ, Srinivasan V (2018) Wear behavior of chitosan-filled polylactic acid/basalt fiber hybrid composites. Adv Polym Technol 37:8

45. Nayak SK, Satapathy A, Mantry S (2020) Processing and wear response study of glass-polyester composites with waste marble dust as particulate filler. Polym Compos 41:2263-2273

46. Nayak SK, Satapathy A (2019) Wear analysis of waste marble dust-filled polymer composites with an integrated approach based on design of experiments and neural computation. Proc Inst Mech Eng J 234:1846-1856

47. Ertane EG, Dorner-Reisel A, Baran O, Welzel T, Matner V, Svoboda S (2018) Processing and wear behaviour of 3D printed PLA reinforced with biogenic carbon. Adv Tribol 2018:1763182

48. Karthik Babu NB, Ramesh T, Muthukumaran S (2020) Physical, tribological and viscoelastic behavior of machining wear debris powder reinforced epoxy composites. J Clean Prod 272:122786

49. Barpanda P, Kulkarni SM, Kishore (2009) Sliding wear behaviour of an epoxy system reinforced with particulate fly ash filler. Adv Compos Lett 18:096369350901800603
50. Zhang S, Cui C, Chen G (2012) Tribological behavior of MC nylon6 composites filled with glass fiber and fly ash. J Wuhan Univ Technol Mat Sci Edit 27:290-295

51. Thakur S, Chauhan SR (2013) Friction and sliding wear characteristics study of submicron size cenosphere particles filled vinylester composites using Taguchi design of experimental technique. J Compos Mater 48:2831-2842

52. Tábi T, Hajba S, Kovács JG (2016) Effect of crystalline forms ( $\alpha^{\prime}$ and $\alpha$ ) of poly(lactic acid) on its mechanical, thermo-mechanical, heat deflection temperature and creep properties. Eur Polym J 82:232-243

53. Di Lorenzo ML, Androsch R (2019) Influence of $\alpha^{\prime}-/ \alpha$-crystal polymorphism on properties of poly(l-lactic acid). Polym Int 68:320-334

54. Zou G-X, Zhang X, Zhao C-X, Li J (2012) The crystalline and mechanical properties of PLA/layered silicate degradable composites. Polym Sci Ser A 54:393-400

Publisher's Note Springer Nature remains neutral with regard to jurisdictional claims in published maps and institutional affiliations. 